\title{
Severe Acute Respiratory Syndrome Coronavirus 2: Concerns for Paediatric Anaesthesiologist
}

\author{
Gyanendra Kumar' ${ }^{*}$, Manoj Sharma² \\ ${ }^{1}$ Department of Paediatric Anaesthesia, Chacha Nehru Bal Chikitsalaya, New Delhi, India \\ ${ }^{2}$ Department of Neuroanaesthesia, AIIMS, New Delhi, India
}

${ }^{\star}$ Correspondence to: Gyanendra Kumar; Department of Paediatric Anaesthesia, Chacha Nehru Bal Chikitsalaya, New Delhi, India;

E-mail: gyanenkumar@yahoo.com

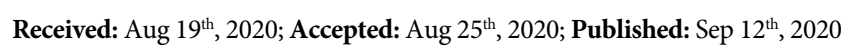

Citation: Kumar G, Sharma M. Severe acute respiratory syndrome coronavirus 2: Concerns for paediatric anaesthesiologist. Biom Case Rep Open A Open J. 2020; I(1): $13-14$

\section{INTRODUCTION}

Coronavirus disease 2019 (COVID-19) is caused by novel coronavirus, now called severe acute respiratory syndrome Coronavirus 2 . World Health Organization (WHO) has declared this outbreak as a "Public health emergency of international concern" (PHEIC) on January 30, 2020. WHO subsequently declared COVID-19 a pandemic on March $11,2020$.

SARS - COV2, infects children less frequently than adults and clinical presentation of COVID-19 symptoms in children are generally milder than that in adult patients. ${ }^{1}$ Paediatric anaesthesiologist will be required to perform airway procedures in children suspected or confirmed of having COVID-19. This may be for children with critical COVID-19 infection who require ventilation, or it may be for children who require surgery.

Management of paediatric patients with suspected or confirmed COVID-19 is also complicated by the need to manage accompanying parents and relatives who are likely to be infected and therefore, presents an infection risk to healthcare providers and other patients.

The risk to paediatric care providers is increased by the higher level of asymptomatic carriers in the young (up to $50 \%)^{2}$

\section{CONSIDERATIONS FOR MODIFICATION OF ANAESTHETICTECHNIQUE IN PAEDIATRIC PATIENT WITH SUSPECTED OR CONFIRMED COVID-19}

As upper respiratory infections (URI) are more common in children, it is impossible to clinically distinguish COVID-19 from other respiratory infection in paediatric patient unless confirmatory test is done.

We need to apply appropriate protocol to reduce viral dissemination and risk of contamination.

\section{PERIOPERATIVE MANAGEMENT}

The Goal is to Minimize Exposure and Prevent Aerosol \& Droplet Generation

Appropriate donning of personal protective equipment is a must.

Child should be wearing a surgical mask during transport to OT. A crying or screaming child will increase the risk of droplet or aerosol spread of the virus, hence strong consideration should be given to administration of a sedative pre-medication. Anaesthesiologist should maintain strict hard hygiene. PPE kits with N95 mask \& face shield should be used routinely.

During induction, positive pressure ventilation using a face mask should be avoided. Intravenous induction with RSI is preferred. If inhalational induction is planned, a tight face mask seal with low flow should be used. A microbiological filter should be placed between the tracheal tube and breathing circuit. Cuffed endotracheal tube is preferred as it minimizes leakage to environment.

Circuit disconnection should be avoided during maintenance. Use of disposable equipment where available.

Smooth \& deep extubation should be tried, as it reduces risk of cough. Although it is unclear whether there is a benefit to deep extubation of patients it has been predictive as protective for aerosol generation. $^{3}$

Covering the patient with transparent plastic barrier minimize contamination of the anaesthesiologist.

Ideally patient with confirmed COVID-19 should be recover negative pressure isolation room. ${ }^{4}$

Entry \& exit point to the OT needs to be tightly controlled and door opening should be kept to a minimum. Minimal staff presence is encouraged especially during intubation \& extubation. ${ }^{5}$ 


\section{Biomedical and Case Reports Open Access Open Journal}

\section{Short Communication}

\begin{tabular}{|l|l|}
\hline \multicolumn{1}{|c|}{ Prevent aerosol and droplet generation } \\
\hline Preoperative preperation & $\begin{array}{l}\text { - Avoid parental presence } \\
\text { - Appropriate donning of PPE } \\
\text { - Minimize crying - premedicate the child } \\
\text { - High efficiency particulate air (HEPA) filter attached to expiratory limb }\end{array}$ \\
\hline - IV induction is preferred \\
- Airway management "SAS" - safe, accurate \& swift5 - Handled by experienced anaesthesiologist \\
- Use of video laryngoscope or C-MAC is recommended \\
- Microcuff tube in infants \& neonates \\
\hline Maintenance & - Circuit disconnection - avoided \\
& $\begin{array}{l}\text { - Use of physical barrier - where possible } \\
\text { Extubation }\end{array}$ \\
\hline - Suctioning \& extubation - in deep plane \\
- Avoid coughing \& vomiting in postoperative period
\end{tabular}

\section{CONCLUSION}

The provision of anaesthesia for the paediatric population during COVID-19 generates unique challenges. It requires special emphasis; guidelines \& protocols are constantly reviewed to provide anaesthesia that is safe for the child and minimizes the risk of infection to health care worker.

\section{FINANCIAL SUPPORT AND SPONSORSHIP}

None.

\section{CONFLICTS OF INTEREST}

None.

\section{REFERENCES}

1. Lu X, Zhang L, Du H, et al. SARS-CoV-2 infection in children. $N$ Engl J Med. 2020; 382: 1663-1635. doi: 10.1056/NEJMc2005073
2. Bialek S, Gierke R, Hughes M, MaNamara, et al. Coronavirus disease 2019 in children - United states, February 12-April 2,2020. Morb Mortal Wkly Rep. 2020; 69: 422-426. doi: 10.15585/mmwr.mm6914e4

3. Matava CT, Kovastsis PG, Lee JK Castro P, et al. Paediatric Airway Management in COVID-19 Patients: Consensus Guidelines From the Society of Paediatric Anaesthesia's Paediatric Difficult intubation Collaborative and the Canadian Paediatric Anaesthesia Society. Anesth Analg. 2020; 131: 61-73. doi: 10.1213/ANE.0000000000004872

4. Lee-Archer P, von Ungern-Sternberg BS. Paediatric anaesthetic implications of COVID-19 - a review of current literature. Paediatr Anaesth. 2020. doi: 10.1111/pan.13889

5. Cook TM, El-Boghdadly K, McGuire B, et al. Consensus guidelines for managing the airway in patients with COVID19: Guidelines from the Difficult Airway Society, the Association of Anaesthetists the Intensive Care Society, the Faculty of Intensive Care Medicine and the Royal College of Anaesthetists. Anaesthesia. 2020; 75: 785-799. doi: 10.1111/ anae.15054 